\title{
Genetic Diversity Assessment in Several Barley (Hordeum vulgare L.) Cultivars Using Microsatellite Markers
}

\author{
Mohammad-Reza BOLOURI-MOGHADAM', AbbasSAFARNEJAD², Kamal S.KAZEMITABAR' \\ ${ }^{1}$ Sari Agricultural Science and Natural Resources University, Faculty of Crop Science, Department of \\ Agronomy, Plant Breeding and Biotechnology, Sari,Iran; kazemi_ka@yahoo.com \\ ${ }^{2}$ Razavi Khorasan Agricultural and Natural Resources Research Center, Mashhad, Iran; sebre14@yahoo.com (corresponding author)
}

\begin{abstract}
In the present study, genetic diversity in seven cultivars of cultivated barley (Hordeum vulgare) populations was evaluated using 10 microsatellite markers. Genomic DNA was extracted from fresh leaves and amplification reactions were done by PCR. The amplification products were separated on $6 \%$ denaturing polyacrylamide gels containing $7 \mathrm{M}$ urea and visualized via silver staining method. High level of polymorphism was observed among populations. Polymorphic bands ranged from 100 to $300 \mathrm{bp}$. Altogether 65 alleles were observed among all genotypes, with an average of 9.2 alleles per locus for all loci. Polymorphic information content (PIC) ranged from 0.80 to 0.88 with an average of 0.84 . 'Sahand' populations showed the lowest mean of gene diversity whereas the highest mean of heterozygosity observed in Rayhan populations that can prepare a powerful resource of genetic diversity for breeding programs. The genotypes were clustered using unweight pair-group method on arithmetic average by POPGEN32 software. The dendrogram discriminated all the genotypes in several groups. The results showed that SSR markers have a high ability to reveal most of the information in a single locus and can be used for genetic analysis in molecular levels determination of genetic similarity and clustering barley cultivars.
\end{abstract}

Keywords: barley, genetic diversity, microsatellite markers, SSR

\section{Introduction}

Utilization of germplasm resources and efficient conservation need ample knowledge regarding the amount of genetic variation in germplasm arrays and genetic relationships between genotypes. Selection of parental combinations that will maximize gain from selection and maintain genetic diversity depends on the information about the amount of genetic variation present, and the location of the genetic determinants of diversity (Matus and Hayes, 2002). Barley, Hordeum vulgare L., is one of the major crops in the world that is cultivated in all temperate areas and is an economically important cereal ranking fourth in world crop production (Hayes et al., 2003). Barley is considered a model species for genetic analysis. Molecular markers have been proved to be valuable tools in the characterization and evaluation of genetic diversity within and between species and populations. Many types of molecular markers have been used to characterize germplasm, with each method differing in principle, application, type and amount of polymorphism detected, cost and time requirement. Microsatellite markers are tandem, 1 to 5, nucleotide repeats found in eukaryotic genomes. SSRs are co dominant, abundant, and informative and their detection can be automated. This makes them excellent molecular marker system for many types of genetic analyses, including linkage mapping, germplasm surveys, and phylogenetic studies (Liu et al., 1996). Most SSRs are highly reproducible and demonstrate a high degree of allelic variation.
Nowadays the effectiveness and informative value of microsatellite markers in genetic studies has been demonstrated for all the major cereals (Sjakste et al., 2003). Microsatellites in barley were also used to study genetic diversity and trace the development of germplasm (Macaulay et al., 2001; Struss and Plieske, 1998). Microsatellite maps for all seven barley chromosomes are now available for the public (Saghai-Maroof et al., 1994; Ramsay et al., 2000).

The objectives of this study were to investigate SSR polymorphism and genetic diversity of 10 microsatellite loci in a set of 7 barley cultivars and to determine the amount of genetic distance and similarity among populations.

\section{Materials and methods}

Seven cultivars of Iranian cultivated barely ('Karoon', 'Valfajr', 'Makooee', 'Reyhan', 'Cb74-2', 'Sahand' and 'Zarjo') were selected for this study. All of these samples were obtained from Research Station of Agricultural and Natural Resources, Khorasan Razavi, Iran.

\section{$D N A$ extraction}

Genomic DNA was extracted from a bulk sampling of a minimum of 20 individuals for each variety using McPherson and Moller (2001) method. Equivalent amounts of DNA from 20 individual plants were pooled as 3 bulked DNA samples for PCR analyses. 
SSR assay

Ten primer pairs (from Metabion International Inc, Germany) were either derived from sequences published previously or designed based on sequences containing tandem repeats from the EMBL and GenBank databases (Tab. 1). PCR amplifications were performed in a total volume of $20 \mu \mathrm{l}$, containing $25 \mathrm{ng}$ of barley genomic DNA, 1x PCR buffer, $0.5 \mathrm{mM}$ both primers, $0.2 \mathrm{mM}$ dNTPs, 2.25 to $3 \mathrm{mM} \mathrm{MgCl}_{2}$ (based on Tab. 1) and 1 unit of Taq polymerase. Amplifications were performed in an Eppendorf thermocycler. PCR amplifications were hot-started at $95^{\circ} \mathrm{C}$ for $4 \mathrm{~min}$, followed by 35 cycles of denaturation at $94^{\circ} \mathrm{C}$ for $50 \mathrm{~s}$, annealing according to Tab. 1 for $45 \mathrm{~s}$ and extension at $72^{\circ} \mathrm{C}$ for $45 \mathrm{~s}$. The final extension was done at $72^{\circ} \mathrm{C}$ for $5 \mathrm{~min}$.

\section{Gel and data analysis}

The amplification products were separated on $1.7 \%$ agarose gel for initial analysis. The 3 primers (Bmac0032, Bmac0223 and Hvm27) which could not produce the product of interest, removed and experiments were continued using other 7 primers. The amplification products were separated on 6\% denaturing polyacrylamide gels and visualized via the silver staining method (Bassam et al., 1991). The resulting gels were scored manually. A similarity matrix using Nei coefficient was generated and the genotypes were clustered using the unweighted pair-group method on arithmetic average (UPGMA) by POPGEN32 software. To measure the informativeness of each SSR, the polymorphism information content (PIC), was calculated using the following formula: PIC $=1-\sum \mathrm{f}_{\mathrm{i}}^{2}$ where $f i$ is the frequency of the $i$ SSR allele (Smith et al., 2000). Shannon information index were calculated for different loci for each population using the following formula:

$$
H^{\prime}=-\sum_{\mathrm{i}=1}^{\mathrm{S}} p_{i} \ln p_{i}
$$

Where $S$ is the number of alleles and $p_{i}$ is the relative abundance of each allele (Hedrick, 1999a).

\section{Results and discussion}

Polymerase chain reaction products were electrophoresed on $1.7 \%$ agarose gel for primary evaluation. The whole primers except Bmac0032, Bmac0223 and HVM27 conducted to products of interest; therefore, the experiments were continued using 7 primers. High levels of polymorphism using these 7 primers were observed after separating PCR products on $6 \%$ polyacrylamide gel. The length of amplified DNA fragments, including microsatellites, ranged from 100 to 300 base pairs. Altogether 65 polymorphic alleles were observed among all genotypes, with an average of 9.2 allele per locus for all loci. At least one allele was observed per population. The number of alleles varied from 7 to 13 alleles per locus with an average of 9.28 alleles per locus. Maximum effective alleles ( 8 alleles) were observed in 'Reyhan' and 'Cb74-2' populations. The rest of the populations except 'Zarjo' and 'Valfajr' had one effective allele. The number of effective alleles among population at different loci ranged from 8.5 (Bmac0134) to 5.12 (Bmac0173) with an average of 6.65 effective allele per locus (Fig. 1).

In this study null alleles were detected at Bmac0173 and HVM7 loci in 'Reyhan' and 'Sahand' cultivars, respectively. The level of polymorphism observed in number of alleles per locus was high and comparable for all polymorphic loci. 'Zarjo' and 'Valfajr' showed the highest (100\%) level of polymorphism, but 'Sahand' populations had a polymorphism level of $71.43 \%$ (Tab. 2). PIC values in this study were quite high and ranged from 0.80 (Bmac0173) to 0.88 (Bmac0134) with an average of 0.84 for SSR markers (Tab. 2). Maximum (0.8006) and minimum (0.5998) mean heterozygosity were observed at 'Reyhan' and 'Sahand' population respectively (Tab. 3). Thus, concerning the polymorphic information content and heterozygosity, 'Sahand' and 'Reyhan' cultivars were the most uniform and the most diverse populations respectively. 'Reyhan' population also showed the highest mean of gene (allele) diversity that indicated high level of heterozygosity in this cultivar.

Tab. 1. Polymerase chain reaction primers and their characteristics

\begin{tabular}{|c|c|c|c|c|c|c|}
\hline Primer & & Sequence $5^{\prime} \rightarrow 3^{\prime}$ & $\mathrm{MW}(\mathrm{g} / \mathrm{mol})$ & $\operatorname{Tm}\left(\mathrm{C}^{\circ}\right)$ & $\mathrm{Ta}\left(\mathrm{C}^{\circ}\right)$ & $\mathrm{MgCl}_{2}(\mathrm{MM})$ \\
\hline HVCMA & $\begin{array}{l}\mathrm{F} \\
\mathrm{R}\end{array}$ & $\begin{array}{l}\text { GCCTCGGTTTGGACATATAAAG } \\
\text { GTAAAGCAAATGTTGAGCAACG }\end{array}$ & $\begin{array}{l}6774 \\
6816\end{array}$ & $\begin{array}{l}58.4 \\
56.5\end{array}$ & $\begin{array}{l}55 \\
55\end{array}$ & 3 \\
\hline Bmac0134 & $\begin{array}{l}\mathrm{F} \\
\mathrm{R}\end{array}$ & $\begin{array}{l}\text { C C A A C T G A G T C G A T C T C G } \\
\text { CTTCGTTGCTTCTCTACCTT }\end{array}$ & $\begin{array}{l}5460 \\
5976\end{array}$ & $\begin{array}{l}56.0 \\
55.3\end{array}$ & $\begin{array}{l}53.1 \\
53.1\end{array}$ & 2.5 \\
\hline Bmac0173 & $\begin{array}{l}\mathrm{F} \\
\mathrm{R}\end{array}$ & $\begin{array}{c}\text { C A T T T T T G T T G G T G A C G G } \\
\text { ATAATGGCGGGAGAGACA }\end{array}$ & $\begin{array}{l}5552 \\
5622\end{array}$ & $\begin{array}{l}51.4 \\
53.7\end{array}$ & $\begin{array}{l}50 \\
50\end{array}$ & 3 \\
\hline HVM9 & $\begin{array}{l}\mathrm{F} \\
\mathrm{R}\end{array}$ & $\begin{array}{c}\text { C T T C G A C A C C A T C A C C C A G } \\
\text { ACCAAAATCGCATCGAACAT }\end{array}$ & $\begin{array}{l}5678 \\
6063\end{array}$ & $\begin{array}{l}58.8 \\
53.2\end{array}$ & $\begin{array}{l}52.5 \\
52.5\end{array}$ & 2.3 \\
\hline HVM7 & $\begin{array}{l}\mathrm{F} \\
\mathrm{R}\end{array}$ & $\begin{array}{l}\text { ATGTAGCGGAAAAAATACCATCAT } \\
\text { CCTAGCTAGTTCGTGAGCTACCTC }\end{array}$ & $\begin{array}{l}7378 \\
7280\end{array}$ & $\begin{array}{l}55.9 \\
64.4\end{array}$ & $\begin{array}{l}58.3 \\
58.3\end{array}$ & 2.25 \\
\hline HVM4 & $\begin{array}{l}\mathrm{F} \\
\mathrm{R}\end{array}$ & $\begin{array}{l}\text { AGAGCAACTACCAGTCCAATGGCA } \\
\text { GTCGAAGGAGAAGCGGGCCCTGGTA }\end{array}$ & $\begin{array}{l}7340 \\
7797\end{array}$ & $\begin{array}{l}62.7 \\
69.5\end{array}$ & $\begin{array}{l}67.2 \\
67.2\end{array}$ & 3 \\
\hline HVM3 & $\begin{array}{l}\mathrm{F} \\
\mathrm{R}\end{array}$ & $\begin{array}{c}\text { ACACCTTCCCAGGACAATCCATTG } \\
\text { AGCACGCAGAGCACCGAAAAAGTC }\end{array}$ & $\begin{array}{r}7242 \\
7374 \\
\end{array}$ & $\begin{array}{l}62.7 \\
64.4\end{array}$ & $\begin{array}{l}61.2 \\
61.2\end{array}$ & 3 \\
\hline
\end{tabular}


142

Tab. 2. Polymorphism values and mean of PIC per population

\begin{tabular}{ccccc}
\hline Population & $\begin{array}{c}\text { Polymorphic } \\
\text { loci }\end{array}$ & $\begin{array}{c}\text { Monomorphic } \\
\text { loci }\end{array}$ & $\begin{array}{c}\text { Polymorphism } \\
(\%)\end{array}$ & PIC \\
\hline 'Karoon' & 18 & 3 & 85.71 & 0.6467 \\
\hline 'Sahand' & 15 & 6 & 71.43 & 0.5998 \\
'Makooee' & 18 & 3 & 85.71 & 0.6468 \\
\hline 'Reyhan' & 18 & 3 & 85.71 & 0.8006 \\
'Cb74-2' & 18 & 3 & 85.71 & 0.6544 \\
\hline 'Valfajr' & 18 & 0 & 100 & 0.7540 \\
'Zarjo' & 21 & 0 & 100 & 0.7593 \\
\hline
\end{tabular}

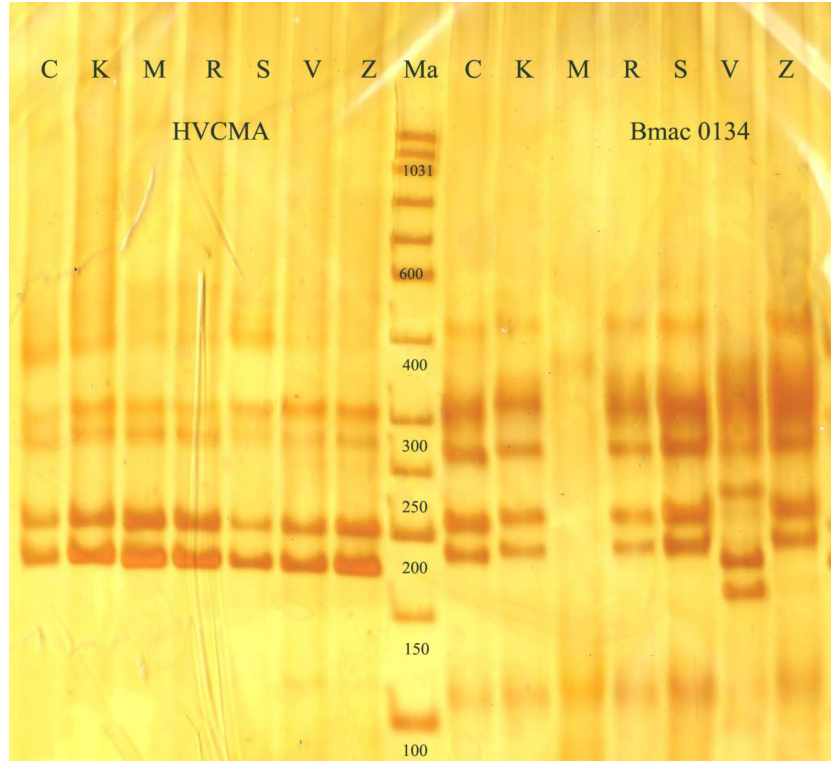

Fig. 1. SSR bands of various cultivars of Barley on $6 \%$ denaturating polyacrylamide gel. $($ Capital letters $=$ first letter of a cultivar name)

The genetic distance $(D)$ among genotypes was estimated based on the proportion of shared alleles. A dendrogram showing the genetic relationships between genotypes was constructed to express the results of cluster analysis based on data obtained by SSR amplification products. The dendrogram discriminated all the cultivars and clustered them separately in 7 groups (Fig. 2). The smallest genetic distance was observed between 'Zarjo' and 'Valfajr' cultivars. The maximum genetic distance observed between 'Sahand' and 'Makooee' populations. Shannon information index and Polymorphic information data (PIC) were calculated for different loci for each population (Tab. 3).

In this study, genomic DNA was extracted from a bulk sample of each variety. The advantages and inconvenience of the bulk analysis have been discussed by Michelmore $e t$ al. (1991) and Loarce et al. (1996). Bulk analyses are economic and rapid, and it is possible to estimate the genetic variability between accessions, whereas it is not possible to obtain information about the genetic variability within the accessions (Fernandez et al., 2002). The number of individual plants bulked for the cultivars is an important experimental factor whether the bulked analysis revealed the genetic relationship between the cultivars. Yang and Quiros (1993) found that the bulked samples with 10, $20,30,40$ and 50 individuals had the same banding pattern. Bustos et al. (1998) also found that bulks of 10 to 20 individuals resulted in the same RAPD profiles. In this study, we used a minimum of 20 individuals for representing each barley variety.

Altogether 65 polymorphic alleles were observed among all genotypes, with an average of 9.2 allele per locus for all loci. Different alleles represented different sizes of the amplification products (Sjakste et al., 2003). The number of alleles ranged from 7 (HVM7 and HVCMA) to 13 (HVM3) alleles per locus. These results were in agreement with the results of Kraic et al. (2002). Maximum effective alleles ( 8 alleles) were observed in 'Reyhan' and ' $\mathrm{Cb} 74-2$ ' populations. The rest of populations except 'Zarjo' and 'Valfajr' had one effective allele. In most cases, each primer pair amplified only one microsatellite allele. This indicates homozygous states in the microsatellite locus but the presence of two or more alleles in some genotypes were observed. These genotypes were regarded as heterozygous at a given locus. Other explanations for this are the presence of two or more sister lines (microsatellite phenotypes), or the presence of an impurity, i.e. non-related genotype(s) in the bulked DNA sample (Kraic et al., 2002). The number of effective alleles among population at different loci ranged from 8.5 (Bmac0134) to 5.12 (Bmac0173) with an average of 6.65 effective allele per locus. When the whole alleles have equal frequency, the number of effective alleles will be equal to $1 / \mathrm{F}$ where $\mathrm{F}$ is the proportion of homozygotes, therefore, the proportion of homozygotes will be in inverse ratio to the number of effective alleles per locus in population. Since the alleles do not have equal frequency, the numbers of effective alleles are smaller than real alleles (Valdes et al., 1993).

In this study null alleles were detected at Bmac0173 and HVM7 loci in 'Reyhan' and 'Sahand' cultivars respectively. We also note that from the perspective of the laboratory investigation the pseudo-death of an allele or locus can occur at any stage in the life cycle due to single (or multiple) nucleotide substitutions, insertions or deletions which occur in flanking regions and prevent primer binding. This process results in null alleles (Callan et al., 1993), which may in time become fixed in the population (Chambers and MacAvoy, 2000). It is now well established that the predominant mutation mechanism in microsatellite tracts is 'slipped-strand mispairing' (Sia et

Tab. 3. Shannon information index and heterozygosity values of barley cultivars

\begin{tabular}{cccccccc}
\hline Population & 'Karoon' & 'Valfajr' & 'Makooee' & 'Reyhan' & 'Sahand' & 'Cb74-2' & 'Zarjo' \\
\hline $\mathrm{H}_{\text {(man) }}$ & 0.6467 & 0.7540 & 0.6468 & 0.8006 & 0.5998 & 0.6544 & 0.7593 \\
$\mathrm{I}_{\text {(man) }}$ & 1.2826 & 1.5350 & 1.2437 & 1.7861 & 1.1484 & 1.3462 & 1.5099 \\
\hline
\end{tabular}




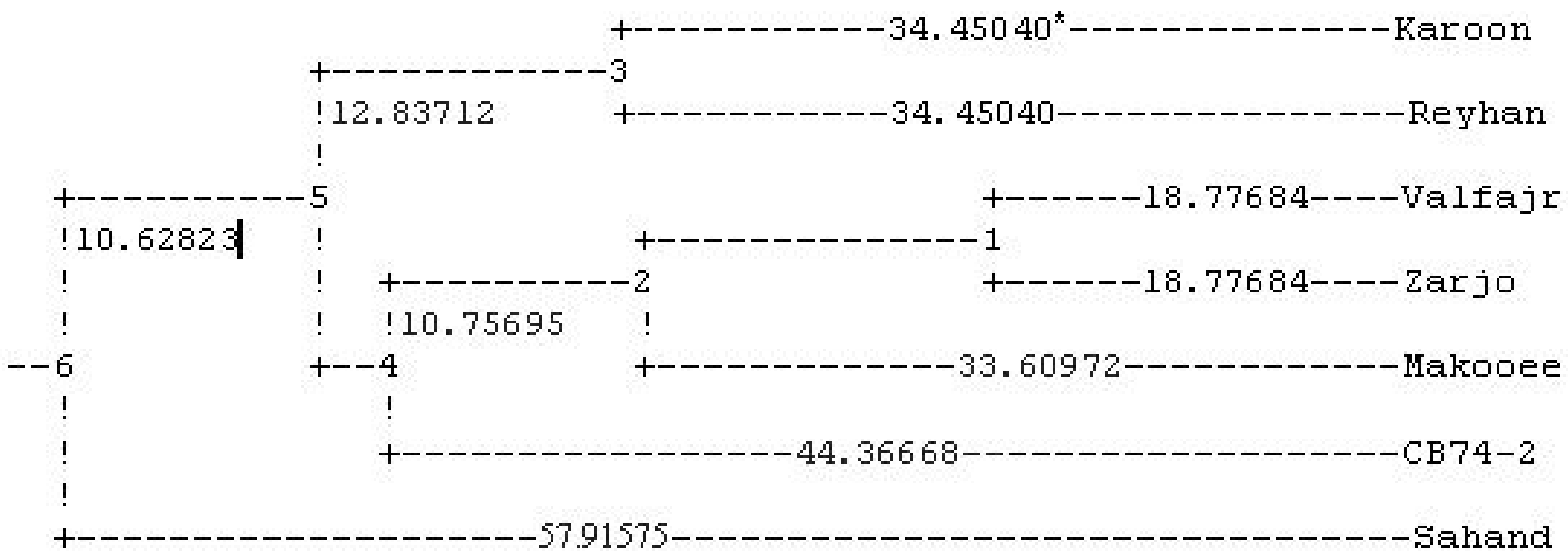

Fig. 2. Dendrogram based Nei's (1972) genetic distance among populations of barley by Popgen $32 .{ }^{*}$ Distances between locations

al., 1997). This process has been well described by Eisen (1999). When slipped-strand mispairing occurs within a microsatellite array during DNA synthesis, it can result in the gain or loss of one, or more, repeat units depending on whether the newly synthesized DNA chain loops out or the template chain loops out respectively.

Since the heterozygotes contain various alleles, their frequency is important as a diversity indicator. Heterozygosity is the most common scale for evaluating genetic diversity in a population (Hedrick, 1999b). Weir (1996) suggested the gene diversity (D) term instead of heterozygosity. Both scales are reported for a locus or average of several loci. However heterozygosity is the most common scale for evaluating allelic variations or effectiveness of a molecular marker (Nei, 1978). It is noticeable that the heterozygosity scales are not sensitive to diversity increase because the extremity of heterozygosity for every number of alleles is equal. This limitation complicates separation of populations using highly variable loci such as microsatellites (with heterozygosity of 0.8 or more). Shannon information index was calculated for different loci for each population:

$$
H^{\prime}=-\sum_{\mathrm{i}=1}^{\mathrm{S}} p_{i} \ln p_{i}
$$

The comparison of heterozygosity values as an interpopulation diversity scale is not accurate for high polymorphic markers such as microsatellites (with heterozygosity of 0.8 or higher) and the differences in such level may not gain exact information. Whereas the maximum value of Shannon's information index is equal to $\operatorname{Ln}(\mathrm{s})$, it may be useful index for measure of diversity of highly variable loci (Hedrick, 1999a). The results of Shannon information index in comparison with heterozygosity or the polymorphism information content (PIC) values indicate that Shannon information index was similar to heterozygosity values and both indices corroborate their results (Tab. 3).

Senior et al. (1998) reported that PIC is synonymous with the term "gene diversity" as described by Weir (1996).
The dendrogram discriminated all the cultivars and clustered them separately in 7 groups (Fig. 2). The smallest genetic distance was observed between 'Zarjo' and 'Valfajr' cultivars that indicate their genetical kinship. The minimum genetic similarity observed between 'Sahand' and 'Makooee' populations indicates their genetical differences that might be due to mutation and/or selection. It is obvious that the measured genetic distance is a proportional distance and if the number of primers changes, the values will change too.

The relationship observed using molecular markers may provide information on the history and biology of cultivars, but it does not necessarily reflect what may be observed with respect to agronomic traits (Métais et al., 2000). The selection process leads to an accumulation of best alleles for the traits under selection (Fernandez et al., 2002). Further morphological and physiological investigations as well as genetic approaches will help to find the exact nature of these genetic variations.

\section{Conclusions}

In general, the results of this study showed that SSR markers have a high ability to reveal most of the information in a single locus and can be used for genetic analysis at molecular level determination of genetic similarity and clustering barley cultivars.

The amplification products were separated on $6 \%$ denaturing polyacrylamide gels containing $7 \mathrm{M}$ urea and visualized via silver staining method. High level of polymorphism was observed among populations. Polymorphic bands ranged from 100 to $300 \mathrm{bp}$. Altogether 65 alleles were observed among all genotypes, with an average of 9.2 alleles per locus for all loci. Polymorphic information content (PIC) ranged from 0.80 to 0.88 with an average of 0.84 . 'Sahand' populations showed the lowest mean of gene diversity whereas the highest mean of heterozygosity observed in Rayhan populations that can prepare a powerful resource of genetic diversity for breeding programs. The genotypes were clustered using unweight pair-group 
144

method on arithmetic average by POPGEN32 software. The dendrogram discriminated all the genotypes in several groups.

\section{References}

Bassam BJ, Caetano-Anolles G, Gresshoff PM (1991). Fast and sensitive silver staining of DNA in acryl amide gels. Anal Biochem 196:80-83.

Bustos AD, Casanova C, Soler C, Jouve N (1998). RAPD variation in wild populations of four species of the genus Hordeum (Poaceae). Theor Appl Genet 96:101-111

Callan DF, Thompson AD, Shen Y, Phillips HA, Richards RI, Mulley JC, Sutherland GR (1993). Incidence and origin of null alleles the $(\mathrm{AC})_{n}$ microsatellite markers. Am J Hum Genet 52:922-927.

Chambers GK, MacAvoy ES (2000). Microsatellites: consensus and controversy. Comparative Biochem Physiol Part B $126: 455-476$

Eisen JA (1999). Mechanistic basis for microsatellilte instability, p. 34-48. In: Goldstein DB, Schlötterer C (Eds.). Microsatellites. Evolution and Applications. Oxford University Press.

Fernandez ME, Figueiras AM, Benito C (2002). The use of ISSR and RAPD markers for detecting DNA polymorphism, genotype identification and genetic diversity among barley cultivars with known origin. Theor Appl Genet 104:845851.

Hayes PM, Castro A, Marquez-Cedillo L, Corey A, Henson C, Jones B, Kling J, Mather D, Matus I, Rossi C, Sato K (2003). Genetic diversity for quantitatively inherited agronomic and malting quality traits. In: Von Bothmer R, Knupfeer $\mathrm{H}$, van Hintum T, Sato K (Eds.). Diversity barley. Amsterdam: Elsevier Science Publishers.

Hedrick PW (1999)a. Genetic of populations. Second edition, Jones and Bartlett Publishers, Sudbury, MA, USA.

Hedrick PW (1999)b. Perspective: Highly variable loci and their interpretation in evolution and conservation. Evolution 53:313-318.

Kraic JN, Gregov E, Jomov K, Hudcovicov M (2002). Microsatellite Markers discriminating accessions within collections of plant genetic resources. Cell Mol Biol 7:745751.

Liu ZW, Biyashev RM, Saghai-Maroof MA (1996). Development of simple sequence repeats DNA markers and their integration into a barley linkage map. Theor Appl Genet 93:869-876.

Loarce Y, Gallego R, Ferrer E (1996). A comparative analysis of genetic relationship between rye cultivars using RFLP and RAPD markers. Euphytica 88:107-115.

Macaulay M, Ramsay L, Powell W, Waugh R (2001). A representative, highly informative 'genotyping set' of barley SSRs. Theor Appl Genet 102:801-809.

Matus IA, Hayes PM (2002). Genetic diversity in three groups of barley germplasm assessed by simple sequence repeats. Genome 45(6):1095-106.
McPherson MJ, Moller, SG (2001). PCR. Oxford: Bios Scientific Publishers.

Métais I, Aubry C, Hamon B, Jalouzot R (2000). Description and analysis of genetic diversity between commercial bean lines Phaseolus vulgaris L. Theor Appl Genet 101:12071214.

Michelmore RW, Paran I, Kesseli RV (1991). Identification of markers linked to disease-resistance genes by bulked segregant analysis: a rapid method to detect markers in specific genomic regions by using segregating populations Proc Natl Acad Sci 88(21):9828-9832.

Nei M (1978). Estimation of average heterozygosity and genetic distance from a small number of individuals. Genetics 89:583-90.

Ramsay L, Macauly M, McLean K, Fuller J, Edwards K, Turesson S, Morgante M, Idegli-Ivanissivich S, Marmiroli N, Maestri E, Massari A, Powell W, Waugh R (2000). A simple sequence repeat-based linkage map on barley. Genetics 156(4):19972005.

Saghai-Maroof MA, Biyashev RM, Yang GP, Zhang Q, Allard RW (1994). Extraordinarily polymorphic microsatellite DNA in barley, species diversity, chromosomal locations and population dynamics. Proc Natl Acad Sci 91:5466-5470.

Senior ML, Murphy JP, Goodman MM, Stuber CW (1998). Utility of SSRs for determining genetic similarities and relationships in maize using an agarose gel system. Crop Sci 38:1088-1098.

Sia EA, Kokoska RJ, Dominska M, Greenwell P, Petes TD, (1997). Microsatellite instability in yeast: dependence on repeat unit size and DNA mismatch repair genes. Mol Cell Biol 17:2851-2858.

Sjakste TG, Rashal I, Der MSR (2003). Inheritance of microsatellite alleles in pedigrees of Latvian barley varieties and related European ancestors. Theor Appl Genet 106:539549.

Smith JSC, Kresovich S, Hopkins MS, Mitchell SE, Dean RE, Woodman WL, Lee M, Porter K (2000). Genetic diversity among elite sorghum inbred lines assessed with simple sequence repeats. Crop Sci 40:226-232.

Struss D, Plieske J (1998). The use of microsatellite markers for detection of genetic diversity in barley populations. Theor Appl Genet 97:308-315.

Valdes AM, Slatkin M, Freimer NB (1993). Allele frequencies at microsatellite loci: the stepwise mutation model revisited. Genetics 133:737-749.

Weir BS (1996). Genetic data analysis II. 2nd ed. Sinauer Associates. Inc. Sunderland, MA.

Yang X, Quiros C (1993). Identification and classification of celery cultivars with RAPD markers. Theor Appl Genet 86:205-212. 